\title{
Correction to: No differences in splenic emptying during on-transient supine cycling between aerobically trained and untrained participants
}

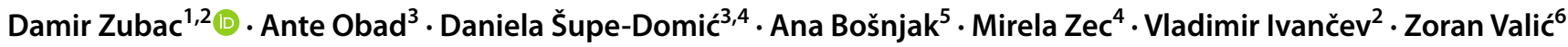

Published online: 10 February 2022

○) Springer-Verlag GmbH Germany, part of Springer Nature 2022

\section{Correction to: European Journal of Applied Physiology https://doi.org/10.1007/s00421-021-04843-w}

The original version of this article unfortunately contained a mistake. There are mistakes in the Table 2. The corrected Table 2 is placed in the following page.

The original article has been corrected.

Publisher's Note Springer Nature remains neutral with regard to jurisdictional claims in published maps and institutional affiliations.

The original article can be found online at https://doi.org/10.1007/ s00421-021-04843-w.

Damir Zubac

damir.zubac@kifst.hr

1 Science and Research Center Koper, Institute for Kinesiology Research, Koper, Slovenia

2 Faculty of Kinesiology, University of Split, Split, Croatia

3 University Department for Health Studies, University of Split, Split, Croatia

4 Department of Medical Laboratory Diagnostics, University Hospital Center Split, Split, Croatia

5 Occupation Medicine Ltd, Metković, Croatia

6 Department of Integrative Physiology, School of Medicine, University of Split, Split, Croatia 


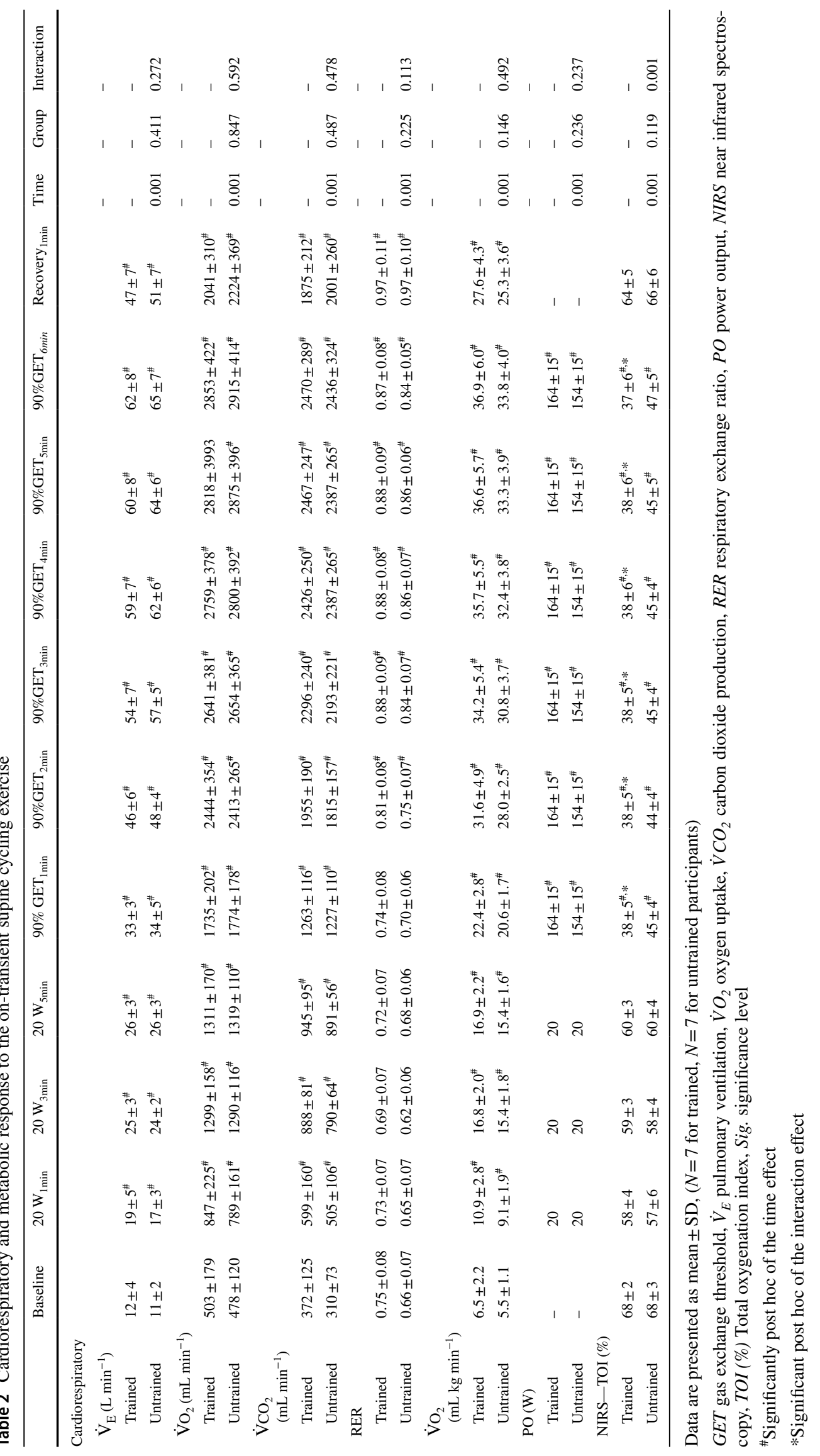

